\title{
From the Editar's Desk
}

Ever increasing demand for Al-Zn-Mg alloys in the construction industry stems from these materials' high strength to weight ratio, toughness and corrosion resistance properties in all weathers. Some of these alloys are being used for the construction of large cylindrical containers and bulk carriers. Augmentation of mechanical properties of thick section Al:Zn-Mg alloys welded joints by introducing variation in the welding technique is demonstrated experimentally by $P$. $K$. Ghosh et al in their paper entitled "Mechanlcal Properties of Pulsed Current Multipass GMA Weld of Al-Zn-Mg alloy". Improvernent of tensile properties of the welded joints has been achieved by using Pulse Current Multipass GMAW process vis-a-vis Continuous Current GMAW process. By varying the pulse current frequency $\left(\mathrm{H}_{2}\right)$ and duration at peak current, zinc dilution and solidification behaviour of the weldmetal have been controlled experimentally. The resultant variation in weidmelal chemistry and concomitant microstructural effects are highlighted in the assessment of tensile properties.

In the paper "General Review of C-Weld in LPG Cylinders", authors K. S. Shamanna et al have discussed areas of technology known to the welders in the field. However, as the domestic use of gas cylinders, as in industry, is increasing by leaps and bounds, an expose of the joining lechniques employed for the LPG cylinders made of $0.2 \% \mathrm{C}$ steel would be welcomed by all users. The necessary care taken by the authors to focus on the benchmark for pressure vessel welding technology, as applicable in this context, is much in evidence for the end users' benefit.

For the welding of pipe joints, particularly those to be used under trying service conditions, special considerations are needed in regard to the design and metallurgical aspects of the weld joint. Author Ron A. Sewell, in his paper "Gas Purging For Weld Root Control in Pipe Welding", has given guidelines for "good" welding practice, in general for tubular butt welding, in order to avoid, for instance, discolouration of stainless steel weld due to oxidation affecting mechanical properties adversely, gas entrapment causing localised embrittlement (hot \& cold) at the parent-weldmetal interface which under corrosive environmental condition could cause unpredictable brittle cracking phenomena.

Easily available, statistically sound data obtained from shop floor welding practices provide the basis for useful statistical analysis of mechanical properties. Author S. Roy in his paper "Investigation Into Optimal Mechanical Properties For Arc Welded Butt joints" provides glimpses of such efforts for structural steel plates welded by industrial welders. Critical analysis of the effects of heat input per mm length of weld and the rate of heat input on tensile strength and hardness of HAZ has been customised for standard statistical techniques for regression analysis, which is an attempt "to predict optimal mechanical properties with respect to welding parameters" and could be availed of as ready reference for design work.

Mining and mineral process industries suffer huge losses due to degradation of machine components from impact on them, erosion and corrosion. Author R. S. Chandel nas carried out extensive and intensive survey work in Canada on this problem. In the first part of his trilogy (IWJ - January 2000 issue), the author has dwelt on reclamation technology counteracting such losses occurring in the mining and allied processing industries, which however could also be effective for wider industrial practices. In the second part of the paper, published in this issue, the author discusses different fusion welding processes suitable for depositing hardfacings, using a wide range of compatible consumables to give required mechanical properties of the deposition. Welder skill, cost of equipment, labour and materials used are also discussed.

After an absence, the 'Quiz' page has reappeard. In this issue, the quiz which has been prepared by Mr. Anupam Haldar. Vice President. IIW, is dedicataed to safety, health and environmental issues. While at it, we request for QuizPage contributions from our readers for the forthcoming issues.

Not to forget IWC-2001 which is only six months or so away. Some details are in page 54 \& 55 . IIW is all geared up for the occasion, but Branches' support is vital for the successful outcome of this prestigious event.

Thank you,

\section{Dr. P Majumdar}

Editor 